$5-1986$

\title{
Two-Step Optimal Thermal Generation Scheduling
}

\author{
B Fardanesh \\ Cleveland State University \\ F. Eugenio Villaseca \\ Cleveland State University, f.villaseca@csuohio.edu
}

Follow this and additional works at: https://engagedscholarship.csuohio.edu/enece_facpub

Part of the Power and Energy Commons

How does access to this work benefit you? Let us know!

\section{Publisher's Statement}

NOTICE: this is the author's version of a work that was accepted for publication in Automatica.

Changes resulting from the publishing process, such as peer review, editing, corrections, structural formatting, and other quality control mechanisms may not be reflected in this document. Changes may have been made to this work since it was submitted for publication. A definitive version was subsequently published in Automatica, 22, 3, (05-01-1986); 10.1016/ 0005-1098(86)90034-8

\section{Original Citation}

Fardanesh, B., , \& Villaseca, F. (1986). Two-step optimal thermal generation scheduling. Automatica, 22(3), 361-366. doi:10.1016/0005-1098(86)90034-8

\section{Repository Citation}

Fardanesh, B and Villaseca, F. Eugenio, "Two-Step Optimal Thermal Generation Scheduling" (1986). Electrical Engineering \& Computer Science Faculty Publications. 75.

https://engagedscholarship.csuohio.edu/enece_facpub/75

This Article is brought to you for free and open access by the Electrical Engineering \& Computer Science Department at EngagedScholarship@CSU. It has been accepted for inclusion in Electrical Engineering \& Computer Science Faculty Publications by an authorized administrator of EngagedScholarship@CSU. For more information, please contact library.es@csuohio.edu. 


\title{
Two-step Optimal Thermal Generation Scheduling*
}

\author{
B. FARDANESH ${ }^{\dagger}$ and F. E. VILLASECA $\dagger$
}

Key Words-Optimization; power generation; scheduling; dynamic programming; computational methods.

\begin{abstract}
A new approach to the solution of the optimal thermal generation scheduling problem is presented. The problem is solved in two steps. As a first step, the optimal production schedule for the next day is obtained based on a daily load forecast, reserve capacity requirements, and present status of generating units. The second-step algorithm uses the results of the first step and adjusts the previous schedule to meet new constraints developed during the course of the day. Variable truncation dynamic programming is proposed as a new method to reduce computation effort. To eliminate the need for solving the entire problem again in the second step, a new technique that limits the solution space to be searched is presented. Use of approach is illustrated via examples.
\end{abstract}

\section{Introduction}

SINCE the late 1950 's the generation scheduling problem, also referred to as unit commitment or pre-dispatch (IEEE, 1971), has been subject of considerable discussion in the power system literature (Gruhl et al., 1975). A non-optimal generation schedule is most likely to offset the savings that are expected through economic dispatch efforts, therefore resulting in an inefficient system operation. Historically, economic dispatch techniques were developed first and then there was a question of how to bring on line or take off line the generating units in the first place (Happ, 1977; Noakes and Arismunder, 1963).

Generally, solution techniques in present unit commitment routines can be categorized either as heuristic or as mathematical programming methods. Heuristic methods (Baldwin et al., 1959; Happ et al., 1971; Kerr et al., 1966) start with an initial feasible solution and use a logical approach to reduce the operating costs in successive refinements. In each iteration, possible savings resulting from advancement or delay of start-up or shut-down of units is sought. When no further improvements are possible, the process ends. Although heuristic methods are flexible and allow for the consideration of actual system operation constraints, there is no guarantee that their solutions are optimal.

Mathematical programming techniques such as dynamic programming (Ayoub and Patton, 1971; Guy, 1971; Kennedy and Mabuce, 1965; Lowery, 1966; Pang and Chen, 1976; Pang $e t$ al., 1981; Rees and Larson, 1971; Waight et al. 1981; Wood, 1982), linear and non-linear programming (Fanshel and Lynes, 1964; Saha and Khaparde, 1978), Lagrangian relaxation (Lauer et al., 1982; Merlin and Sandrin, 1983), and branch-and-bound based methods (Lauer et al., 1982; Mukstadt and Wilson, 1968), have been proposed to solve different formulations of the problem.

In dynamic programming based solutions, for each time interval (usually an hour), different combinations of units which render feasible solutions to the problem are considered. Economic dispatch is performed for each combination to calculate the total production cost for that combination. Some dynamic programming formulations implement approximate economic dispatch subroutines (Pang and Chen, 1976) in order to save computation time. System losses are usually neglected. Some studies include system losses in the total forecasted system demand (Merlin and Sandrin, 1983).

Application of non-linear programming techniques is limited only to greatly simplified problems. Consideration of the pertinent constraints results in a non-convex and nondifferentiable problem which is not amenable to non-linear programming solutions. Linear programming methods do not generally present satisfactory solutions due to the level of approximation introduced by linearizing the problem.

More recent studies obtain a solution for the dual of the original problem and combine this approach with the branchand-bound technique and solve a mixed-integer programming problem (Lauer et al., 1982; Mukstadt and Wilson, 1968). This approach, also referred to as Lagrangian relaxation, exploits the separable structure of the problem to keep computation time and memory requirements for large systems in a manageable range, and result in near optimal solutions (Merlin and Sandrin, 1983).

Here, a new approach to the optimal thermal generation scheduling problem is proposed. Basically, the problem is solved in two steps. As a first step, the optimal production schedule for the next day is obtained based on daily load forecast, reserve capacity requirements, and present status of generating units. Dynamic programming is used in this first-step optimization routine and many practical and realistic constraints are considered. The second-step algorithm. consisting of a fast routine, uses the results of the first step and adjusts the previous schedule to meet the new constraints developed during the course of the day without solving the entire problem again. It also provides the corresponding gain or loss in operating costs resulting from a change in the schedule. Although this approach is looked upon as a two-step solution to the problem, the secondstep routine can be used repeatedly to update a given schedule or to study the effects of a certain change in such a schedule. These studies use the first-step schedule as reference.

\section{Problem definition}

Consider a power system with $N$ generating units over a time horizon of $M \mathrm{hr}$. The time horizon is divided into smaller time intervals, normally of $1 \mathrm{hr}$ duration, so that there are $M$ time intervals in the horizon. An integrated hourly demand will be used over each hourly interval. This constant quantity will be taken as the total hourly demand for the system. The problem is:

$$
\underset{x}{\operatorname{Minimize}} Z=\sum_{t=1}^{M}\left[\sum_{j \in \gamma_{k}^{t}} C_{j}^{t}\left(P_{j}^{t}\right)+\sum_{j \in \gamma_{t}^{t}} T_{j}^{t}\left(P_{j}^{t-1}, P_{j}^{t}\right)\right]
$$

where $Z=$ Total cost of generation for the considered horizon, $M=$ number of hourly intervals in the horizon,

$P_{j}^{\prime}=$ generation assigned to unit $j$ in time interval $t[\mathrm{MW}]$,

$C_{j}=$ cost function for unit $j\left[\$ \mathrm{hr}^{-1}\right]$.

$T_{j}^{i}=$ transitional costs for unit $j$ (i.e. start-up and shut-down costs) in going from a state in time interval $t-1$ to a state in time interval $t\left[\$ \mathrm{hr}^{-1}\right]$.

$\alpha=\left\{\gamma^{1}, \gamma^{2}, \ldots, \gamma^{M}\right\}=$ set of unit combinations for the entire horizon,

$\gamma^{\prime} \in \delta(\eta)=$ a single unit combination in time interval $t$ $\eta=\{1, \ldots, n\}=$ set of all units

$\delta(\eta)=\{\beta \mid \beta \subseteq \eta\}=$ power of set $\eta$,

$n=$ total number of units subject to the following set of constraints. 
Generation load hadance innstraint

$$
\sum_{l=1} P_{1}=P_{D}+P_{l}
$$

where $P_{D}^{\prime}=$ total system demand in time interval $t$ [MW]. $P_{L}^{t}=$ total system transmission losses in time interval $t[\mathrm{MW}]$.

Spinning reserve constraints: To minimize service interruptions to the consumers, it is necessary to maintain a certain amount of spinning reserve capacity. For a given on-line unit. its spinning reserve is the lesser of the maximum allowable spinning reserve on the unit, and the unit capacity less the unit generation. The maximum allowable spinning reserve on a unit is specified to reflect the load pick-up capability of the unit which in turn depends on the type of unit. The amount of spinning reserve capacity maintained can be a fixed percentage of the system peak demand or it can be taken to be equal to the capacity of the most heavily loaded unit in the system. Spinning reserve is necessary to assure reliable service in case of equipment outages or unpredicted load fluctuations in the system.

Transmission system configuration and unit characteristics impose other spinning reserve related constraints. A minimum spinning reserve capacity must be maintained by each area and each plant within the system to assure a geographic distribution of the reserve and the operation within the transmission system limits.

$$
\begin{aligned}
& \sum_{j, i t} \min \left(P_{j_{\text {mat }}}^{t}-P_{j}^{t}, \operatorname{MAXSR} R_{j}^{t}\right) \geqslant \operatorname{SSRR}^{t} \\
& \sum_{j \in ;: N} \min \left(P_{J_{\max }}^{t}-P_{j}^{t}, \operatorname{MAXSR}_{i}^{t}\right) \geqslant \operatorname{ASRR}^{t} \quad N=1.2, \ldots L
\end{aligned}
$$

$P_{j \max }^{t}=$ maximum generation level (capacity) of unit $j$ in time interval $t[\mathrm{MW}]$

$\operatorname{MAXSR}_{j}^{\prime}=$ maximum spinning reserve allowed on unit $j$ in time interval $t[\mathrm{MW}$,

$\mathrm{SSRR}^{\prime}=$ system reserve requirement in time interval $t[\mathrm{MW}]$,

ASRR $^{\prime}=$ area spinning reserve requirement in time interval $t$ $[\mathrm{MW}]$.

$\dot{\delta}_{N}=$ set of units in area $N\left(\delta_{N} \subset \eta\right)$

$l=$ number of areas in the system.

Lnit capacity limits: $P_{\text {jmixs }} \leqslant P_{i} \leqslant P_{\text {jmax }}$

where $P_{j_{\max }}=$ maximum capacity of unit $j$

$P_{j_{\min }}=$ minimum capacity of unit $j$

Unit minimum up time and minimum down time: Limitations on successive start-up and shut-down of units are imposed due to manufacturer's recommendation based on mechanical considerations. Once a unit is brought on line it has to stay on line for a minimum specified number of hours. Similarly a shut-down unit must remain down for a specified minimum number of hours before it can be brought on line again.

Must-run units: These units must be on line due to reliability measures or voltage level maintenance at certain bus and/or economic considerations.

Units assigned to fixed generation status: These units are automatically must-run units and they generate at a specified fixed level.

Crew constraints on plants: Due to limited staff size in some plants it would be impossible to start up or shut down two or more units at the same time. These constraints are specified considering the time required to start up or shut down a unit.

Changes in unit status and characteristics: Provisions are made to change the status of the units and capacity limits in the process of the solution. For example, an unavailable unit can be made available or an available unit can be assigned to fixed generation status at a specified level. in any time interval.

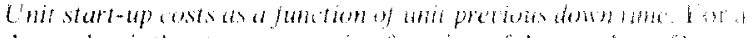
thermal unit the start-up cost is a function of the number of hattl that the unit has been down. The reason is that the kneer the unit is down the cooler the boiler will get and therefore it would by more costly to bring the unit on line. The relationship between start-up costs and previous down time of a unit sencralls acknowledged to be exponential.

$$
S C \cdots C(S)+t^{\prime}+B
$$

where

$\mathrm{SC}=$ unit start up cost $[\$]$

$\mathrm{CCS}=$ cost of cold start $[\$]$

$i=$ cooling rate $\left[\mathrm{hr}^{-1}\right]$.

$\mathrm{B}=$ fixed costs involved in startup te.g. maintenance costs and crew expensesi.

\section{First-step algorithm}

Optimal generation scheduling is most amenable to a forward dynamic programming solution due to its particular structure. Logically the problem can be decomposed into time intervals which constitute the stages of the problem. At each stage or time interval the problem is completely defined by a combination of generating units which satisfies all the constraints, and the operating cost associated with that combination. This is defined as the state of the problem. At each stage the problem might have several allowable states. The transition from a unique state in a stage to another state at another stage occurs by effecting feasible controls which are the decisions made in regard to start-up or shut-down of generating units. A given combination of units at each stage is dependent on a state in the previous stage and the applied controls in the transition. The problem can be solved recursively using forward dynamic programming (Pang and Chen, 1976).

Assuming hourly time intervals, the recursive algorithm at hour $T$ with combination $K$ is

$\operatorname{CUMC}(T . K)=\min [\operatorname{PCOST}(T, K)+\operatorname{TCOST}(T-1 . I: T, K)$ I!:

$+\operatorname{CUMCIT-1,11}$

where

CUMC $(T, K)=$ minimum total cost to arrive at state $(T, K)$. $\operatorname{PCOST}(T, K)=$ production cost for state $(T, K)$

$\operatorname{TCOST}(T-1, I: T, K)=$ transitional (start-up and shut-down) costs from state $(T-1, I)$ to state $(T, I)$.

$I=$ set of combinations at hour $T-1$

Since thousands of economic dispatch problems must be solved in the generating schedule problem. in this study an efficient but suboptimal approach proposed by Wood (1982), is adopted to consider the reserve constraints in the economic allocation of generation and reserve.

Pang and Chen (1976) introduced the concept of truncated dynamic programming for optimal scheduling of thermal units. In their method, priorities are assigned to different units and a unit selection list is formed. A higher priority corresponds to a more economic unit. After formulation of the unit priority list, the minimum number of units with highest priority that satisfy load plus reserve requirements are assigned to must-run status. Then a search window is placed around the lowest priority unit assigned to must-run status, which could include a number of units directly above and a number of units directly below this unit in the priority list. The number of units in the search window is specified by the user. Furthermore, the authors suggest a control over the computational requirements by limiting the number of the feasible states saved at each hourly interval. However. once the level of truncation is chosen. it is uniformly applied to all hourly intervals in the horizon.

A new method for effecting the truncations in the dynamic programming solution algorithm is proposed in this study. The new method suggests a variable level of truncation based on the forecasted load profile. For example, if the number of saved strategies is considered, a high and a low value for the number of saved strategies is specified by the user. The sequence of unit combinations leading from a state at an interval to at state at 
another interval is defined as a strategy.

A criterion is developed which identifies the time periods where a high number of strategies must be saved. This criterion is based on the variation of the demand in the forecasted load profile. Investigations and studies on the nature of full dynamic programming solutions in the entire solution space indicate that during the periods of little or no ramping (high rate of increase or decrease of the demand) it is highly probable that the set of states (and the associated strategies) which contains the optimal strategy, consists of the minimum cumulative cost state and a few of the states with cumulative costs closest to the minimum. In other words, a small subset of the set of all feasible strategies needs to be saved and examined during the solution process. On the other hand, during the periods of high ramping a larger number of the feasible strategies need to be saved as compared to the periods of little or no ramping. This conclusion seems quite logical considering the fact that it is more likely to have generating units started up or shut down during the periods of high ramping. Consequently, there is a higher chance for a strategy with a larger cost gap (between the cumulative cost of this strategy and the minimum cumulative cost strategy) to be selected as part of the optimal trajectory. The higher cost of the chosen strategy, if it is to be the optimal choice, must be compensated for, and extra savings must be obtained due to savings in production and start-up costs in the future states resulting from the chosen strategy.

The algorithm developed to identify the high ramping periods is simple. For each hourly interval a "demand change step" which is the absolute value of the change in demand from the present hour to the next hour is obtained. Then, an average "demand change step" is calculated for the entire horizon. If the demand change step from any interval $t$ to the interval $t+1$ is larger than the average "demand change step", the specified high value is used for the number of the strategies that must be saved in the time interval $t$. Otherwise the specified low value is used.

The variable number of saved strategies is meritorious since it produces the same result, as obtained by choosing the high number of saved strategies for the entire horizon, and requires less computation time. It should be noted that if the number of strategies is too small, the gap between the obtained solution and the global minimum might be unacceptably large and there is even the possibility of not finding any feasible solution in some time interval. Too large a number of saved strategies on the other hand, although it increases the chance of finding a better solution or even the optimal solution, might drive the computational requirements beyond the limits. The suggested method of variable number of saved strategies increases the chance of the optimal trajectory being included in the solution space searched during the periods of high ramping where the optimal trajectory is most likely to be missed.

Although the above discussion is centred on the number of saved strategies at each interval, the same algorithm may be used to effect variable search window sizes (Pang and Chen, 1976; Pang et al., 1981), and increase the possibility that the combinations that constitute the optimal trajectory be included in the searched solution space.

Adequate high and low parameter values for a specific system must be obtained by experimentation as follows. Successive trials with fixed truncations (equal high and low values) can lead to a high parameter that most often results in the same solutions as obtained by full dynamic programming. A proper value for the low parameter can then be obtained in a similar fashion. The stability shown by these parameters under a diverse class of studies (Fardanesh, 1985), would justify the preliminary effort required for their experimental determination.

\section{Second-step algorithm}

The second-step scheduling algorithm operates on a previously obtained optimal schedule to incorporate changes in the original schedule necessary to meet the new constraints developed during the course of the day or to satisfy any violated constraint due to unexpected events. It also provides the corresponding gain or loss in the operating costs resulting from a change in the schedule.

Computational efficiency is the most important feature of the second-step algorithm. Savings in the computational effort are effected by limiting the solution space to be searched based on the previously obtained optimal schedule.
Consider two distinct situations, which may arise when changes to a schedule need to be introduced: extra capacity needs to be scheduled or scheduled capacity needs to be reduced. Clearly, both actions may be required during the horizon of the schedule, but, for convenience, they will be treated separately in the discussion below.

If extra capacity needs to be scheduled, it is highly probable that the original set of units plus new units, if necessary, will satisfy the requirements. In other words, it is highly likely that there would be no unit replaced in the original set of units by any off-line available unit. This has been confirmed through a detailed study of the solutions obtained for many different cases (Fardanesh, 1985). This low probability of unit replacement can be taken advantage of, to effect a controlled reduction in the computational efforts. This results from the fact that the solution space to be searched is now limited only to the available off-line units plus a selected number of the units originally scheduled to be on-line by the first step routine. These selected units will be examined for possible replacement. These units are well identified by the first step schedule itself.

Let $\mathrm{IND}=0,1,2, \ldots$, represent the index measuring the increase in computational effort. If IND $=0$, the search space includes only the off-line but available units. That is, no unit from the original set is to be replaced. If IND $=1,2 \ldots$, each unit shut down in the first step schedule will be included in the search space for $1,2, \ldots$ hours, respectively, before the shut-down; and each unit started up in the first step schedule will be included in the search for $1,2, \ldots$ hr, respectively, beginning with the start-up hour.

For example, consider a system with eight generating units with an original schedule over a 12-hr horizon obtained by the first step algorithm as shown in Figure 1a. Without loss of generality, the units have been numbered from 1 to 8 and zeros indicate that the unit is off-line but available. Thus, the non-zero entries on a given column indicate the on-line units for that hour. The search spaces for IND $=0,1$, and 2 are indicated in Figures $1 \mathrm{a}, \mathrm{b}$, and $\mathrm{c}$, respectively.

Now consider the case when the scheduled capacity needs to be reduced. The solution space to be searched is limited to the units scheduled to be on-line by the first step plus a selected number of off-line available units. If IND $=0$, the solution space to be searched includes only the on-line units. That is, only the on-line units are considered for possible shut-down. If IND $=1,2, \ldots$,

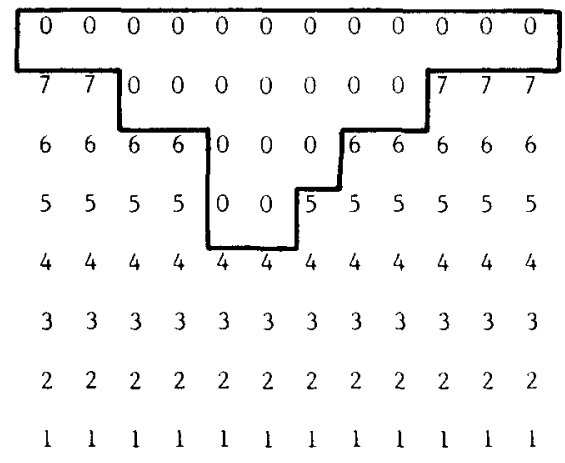

FIG. 1(a). The search space for IND $=0$.

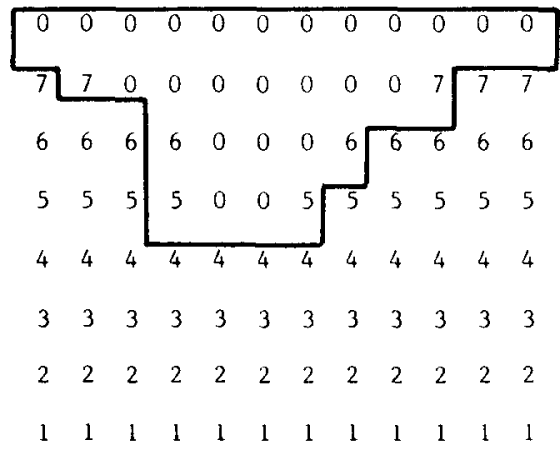

FIG. 1(b). The search space for IND $=1$. 


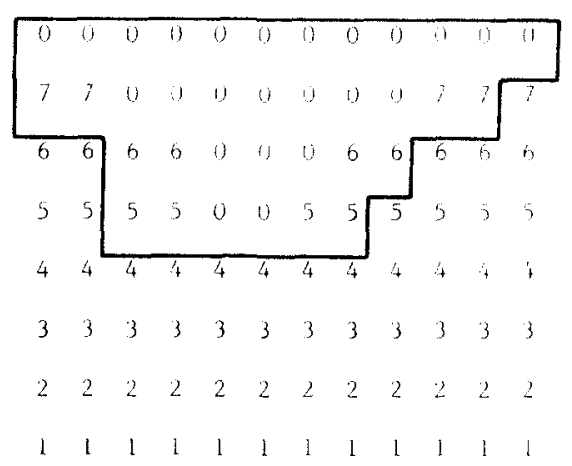

FIG. 1(c). The search space for IND $=2$.

each unit shut down in the first step schedule will be included in the search space for $1,2, \ldots \mathrm{hr}$, respectively, beginning with the shut-down hour; and each unit started up in the first step schedule will be included in the search for $1,2, \ldots$ hr, respectively, before the start-up hour.

For the same example, for a period of reduction in schedule capacity, the search ranges for IND $=0,1$ and 2 are shown in Figs $2 a, b$ and $c$ respectively.

$\begin{array}{llllllllllll}0 & 0 & 0 & 0 & 0 & 0 & 0 & 0 & 0 & 1 & 0 & 0\end{array}$

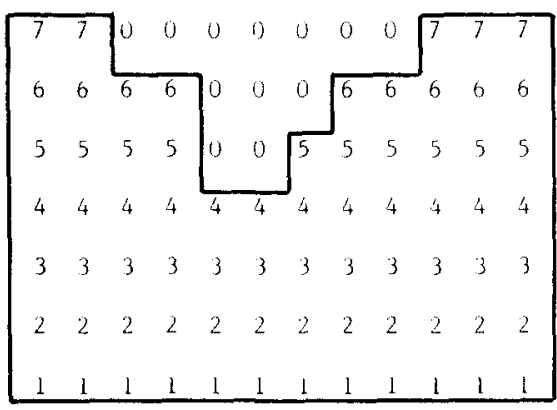

FIG. 2(a). The search space for IND $=0$.

$\begin{array}{llllllllllll}0 & 0 & 0 & 0 & 0 & 0 & 0 & 0 & 0 & 0 & 0 & 1\end{array}$

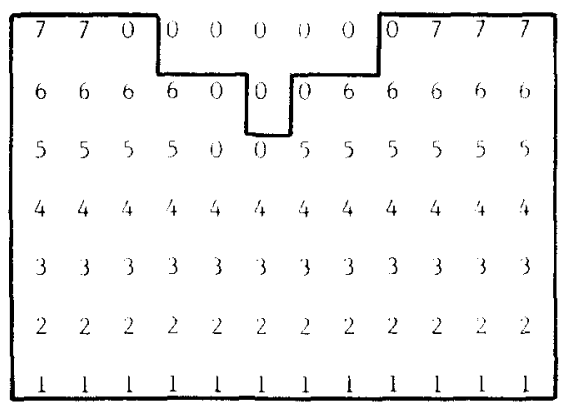

FIG. 2(b). The search space for IND $=1$.

$\begin{array}{llllllllllll}0 & 0 & 0 & 0 & 0 & 0 & 0 & 0 & 0 & 0 & 0 & 0\end{array}$

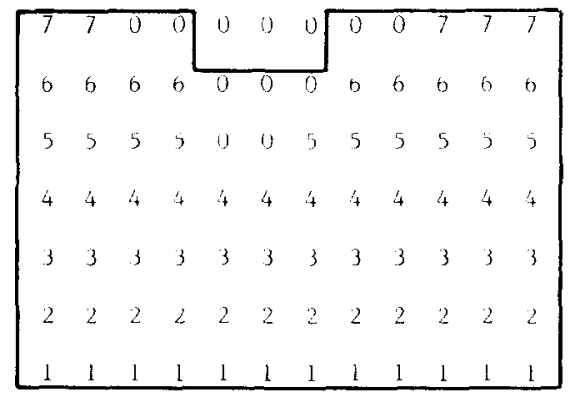

Fig. 2(c). The search space for IND $=2$.
The problem formulation for the second step uptimizalimit routine is similar to the first step algorithm. except to th: reduced size of the set $\alpha$, which is the set of unit combinations fis: the entire horizon. The same type of constraints can be imposed with the necessary changes indicating the new requirements to be satisfied. Forward dynamic programming method is used i, minimize the cost increase due to the new requirements. Th recursive search algorithm at hour $l$ with combination $\mathrm{K}$ h

$\Delta C C(T, K)=\min [\Delta P C(T, K)+\Delta T C I T-1 . I: T K)$

$$
+\Delta C(T-1, I)
$$

where $\Delta C C(T, K)=$ minimum increase in total cost to arrive at state $(T, K)$

$\Delta \mathrm{PC}(T, K)=$ increase in production cost for state $(T, k)$

$\Delta \mathrm{TC}(T-1, I: T, K)=$ increase in transitional costs from statc $(T-1 . I)$ to state $(T, K)$.

$\{I\}=$ set of unit combinations at hour $T-1$.

\section{Examples and results}

The algorithms for first-step and second-step solutions were developed and used to test their merits. These were coded in FORTRAN IV, and run on an IBM-3081.

The power system utilized in these studies consists of 20 thermal units, whose characteristics are given in Table J. Tho parameters for the cost and start-up functions of each unit are listed in Table 2 . In addition to above information, other input data include hourly system load levels over a 24 -hr period, total reserve requirements for each area. In these tables, $\mathrm{UNO}=$ the unit number; $F=0,1.2$, indicating unit not available, unit available and unit assigned to must-run status, respectively. $\mathrm{PN}=$ plant number $\mathrm{A}=$ area number: $\mathrm{PMAX}=$ unit maximum generation capacity; $\mathrm{PMIN}=$ unit minimum generation capacity; $\quad \mathrm{SRM}=$ unit maximum spinning rescrv; $\mathrm{MU}=$ minimum up time; $\mathrm{MD}=$ minimum down time; $\mathrm{PS}=0$. 1 , indicating unit previously down and previously up. respectively $; \mathrm{OH}=$ number of hours unit has been on previousiy and $\mathrm{FH}=$ number of hours unit has been off previously. where the unit cost function is given by

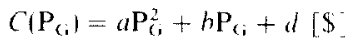

and

$$
\text { CCS, } ; \text { and } B=0
$$

are the parameters of the start-up function defined above.

\begin{tabular}{|c|c|c|c|c|c|c|c|c|c|c|c|}
\hline UNO & $\mathrm{F}$ & PN & A & PMAX & PMIN & SRM & MU & MD & PS & $\mathrm{OH}$ & FH \\
\hline 1 & 2 & 1 & 1 & 550 & 250 & 110 & 30 & 15 & 1 & 11 & \\
\hline 2 & 2 & 1 & 1 & 550 & 250 & 110 & 30 & 15 & $\mathrm{i}$ & $1: 1$ & \\
\hline 3 & 2 & 1 & 1 & 520 & 250 & 104 & 30 & 15 & 1 & 8 & 1 \\
\hline 4 & 2 & 3 & 1 & 520 & $251)$ & 104 & 30 & 15 & 1 & 8 & \\
\hline 5 & 2 & 2 & l & 443 & 125 & 100 & 20 & 10 & $!$ & 7 & \\
\hline 6 & 2 & 2 & $i$ & 443 & 125 & 100 & 20 & 10 & 1 & 7 & \\
\hline 7 & 2 & 2 & 1 & 320 & (21) & 70 & 5 & 2 & 1 & $n$ & \\
\hline 8 & 2 & 2 & 1 & 320 & 120 & 70 & 5 & 2 & 1 & $n$ & \\
\hline 9 & 2 & 3 & 1 & 280 & 75 & $60 !$ & 5 & 2 & $i$ & $\because$ & \\
\hline 10 & 1 & 3 & L & 280 & 73 & bu & 5 & 2 & $i$ & ; & \\
\hline 11 & 1 & 3 & l & $1+8$ & 50 & 90 & 5 & 1 & 1 & $\therefore$ & \\
\hline 12 & 1 & 1 & 1 & 148 & 510 & 90 & 5 & l. & li & 1 & \\
\hline 13 & 1 & 1 & L & 118 & 25 & $9 i 1$ & 0 & 0 & 0 & $\therefore$ & \\
\hline 14 & 1 & 3 & 1 & 118 & 25 & 90 & j & 0 & 0) & 3 & \\
\hline 15 & 1 & 3 & i & 100 & 30 & 70 & 0 & 0 & v & i) & \\
\hline 16 & l & 3 & 1 & 100 & 30 & 70 & 0 & 0 & 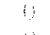 & +! & \\
\hline 17 & 0 & 2 & 1 & 80 & $2 i 1$ & 50 & 0 & 0 & $y$ & 1. & \\
\hline 18 & 0 & 2 & l & 80 & 2!) & 50 & $v$ & 0 & ; & 1) & \\
\hline 19 & u & 1 & l & 60) & 15 & 30 & 0 & 1) & 1 & ! & 3 \\
\hline 20 & 0 & 1 & 1 & 60 & 15 & 30 & 0 & 0 & 1 & ij & \\
\hline
\end{tabular}

The first set of runs were designed to compare the results

TABle 1. Unit characteristics 
Table 2. Parameters of cost and start-up functions

\begin{tabular}{cccccc}
\hline UNO & $\mathrm{a}$ & $\mathrm{b}$ & $\mathrm{d}$ & $\mathrm{CCS}$ & $\lambda$ \\
\hline 1 & 0.00135 & 1.1285 & 100. & 282. & .1 \\
2 & 0.00132 & 1.1265 & 110. & 262. & .1 \\
3 & 0.00127 & 1.1954 & 105. & 267. & .1 \\
4 & 0.00125 & 1.1854 & 115. & 227. & .1 \\
5 & 0.00148 & 1.2136 & 82. & 227. & .2 \\
6 & 0.00140 & 1.1136 & 92. & 207. & .2 \\
7 & 0.00289 & 1.2643 & 49. & 187. & .2 \\
8 & 0.00280 & 1.2443 & 69. & 157. & .2 \\
9 & 0.00261 & 1.5354 & 72. & 176. & .1 \\
10 & 0.00291 & 1.7354 & 52. & 156. & .1 \\
11 & 0.00212 & 1.8015 & 29. & 113. & .1 \\
12 & 0.00282 & 1.7015 & 59. & 103. & .1 \\
13 & 0.00382 & 1.6966 & 32. & 94. & .1 \\
14 & 0.00302 & 1.6066 & 42. & 99. & .1 \\
15 & 0.00393 & 1.8518 & 40. & 114. & .1 \\
16 & 0.00393 & 1.8518 & 40. & 114. & .1 \\
17 & 0.00396 & 1.9161 & 25. & 101. & .1 \\
18 & 0.00396 & 1.9161 & 25. & 101. & .1 \\
19 & 0.00510 & 2.2034 & 15. & 85. & .3 \\
20 & 0.00510 & 2.2034 & 15. & 85. & .3 \\
\hline
\end{tabular}

obtained using a fixed number of saved strategies against the variable number proposed in this study. These are shown in Table 3, where six runs are presented.

Table 3 shows three test cases with three different load profiles. Comparison of the total costs and the CPU times indicates about $30 \%$ reduction in computation time for each case when the variable truncation method is used.

In Case 1, the problem solved has the same specifications as Case 0 , except that the hourly demand is decreased by $100 \mathrm{MW}$. Case 2 shows the results for a $100 \mathrm{MW}$ increase in hourly demand over case 0 .

Cases 1 and 2 are used to illustrate the solution obtained by the second-step algorithm which uses the Case 0 results as reference.

In Case 2 of Table 4, IND $=0$ does not result in the optimal solution and the next higher search level (IND = 1) is needed to find it. Considerable reduction in CPU time, compared to the first-step algorithm solutions with high and low values of 15 and 4 , indicates the efficiency of the second-step algorithm. Even faster results are possible by incorporating the variable truncations in the second-step algorithm. These are also illustrated in Table 4.

\section{Conclusion}

The solution of the optimal generation scheduling problem in two steps has been proposed. This formulation allowed the introduction of two new dynamic programming techniques: variable truncation dynamic programming and limitation of the solution space to be searched. Use of the former in the first step and, particularly, of both in the second step, is shown to be capable of producing the same solutions as those obtained by full

TABLE 3. First-step results

\section{First-Step Results with Full Dynamic} Variable and Fixed Trunc. Programming Results

\begin{tabular}{cccccc}
\hline & S.S.* & Total Costs & CPU & Total Costs & CPU \\
Case $\mathrm{H} \quad \mathrm{L}$ & $(\$)$ & $(\mathrm{sec})$ & $(\$)$ & $(\mathrm{sec})$ \\
\hline
\end{tabular}

\begin{tabular}{|c|c|c|c|c|c|c|}
\hline Case & $\mathrm{H}$ & $\mathrm{L}$ & (\$) & $(\mathrm{sec})$ & $(\$)$ & $(\mathrm{sec})$ \\
\hline \multirow{3}{*}{0} & 15 & 15 & $186,039.3$ & 41.22 & \multirow{3}{*}{$186,039.3$} & \multirow{3}{*}{323.26} \\
\hline & & & & & & \\
\hline & 15 & 4 & $186,039.3$ & 27.45 & & \\
\hline \multirow{3}{*}{1} & 15 & 15 & $180,049.4$ & 44.90 & \multirow{3}{*}{$180,049.4$} & \multirow{3}{*}{356.20} \\
\hline & & & & & & \\
\hline & 15 & 4 & $180,049.4$ & 30.67 & & \\
\hline \multirow{2}{*}{2} & 15 & 15 & $192,086.8$ & 40.33 & \multirow{2}{*}{$192,086.8$} & \multirow{2}{*}{280.08} \\
\hline & 15 & 4 & $192,086.8$ & 27.30 & & \\
\hline
\end{tabular}

\footnotetext{
$\star_{\mathrm{S} . \mathrm{S} .}=$ Number of saved strategies.

$\mathrm{H}=$ High value

$\mathrm{L}=$ Low value
}

TABLE 4. Second-step results

\begin{tabular}{|c|c|c|c|c|c|}
\hline & \multicolumn{3}{|c|}{$\begin{array}{l}\text { Second-Step with } \\
\text { No Truncation }\end{array}$} & \multicolumn{2}{|c|}{$\begin{array}{l}\text { Second-Step with } \\
\text { Variable Truncation } \\
\mathrm{H}=15\end{array}$} \\
\hline Case & IND & $\begin{array}{c}\text { Total Costs } \\
(\$) \\
\end{array}$ & $\begin{array}{r}\mathrm{CPU} \\
(\mathrm{sec}) \\
\end{array}$ & $\begin{array}{c}\text { Total Costs } \\
(\$)\end{array}$ & $\begin{array}{r}\mathrm{CPU} \\
(\mathrm{sec}) \\
\end{array}$ \\
\hline \multirow{2}{*}{1} & 0 & $180,049.4$ & 3.23 & $180,049.4$ & 2.93 \\
\hline & 1 & $180,049.4$ & 5.83 & $180,049.4$ & 4.13 \\
\hline \multirow{2}{*}{2} & 0 & $192,088.4$ & 7.19 & $192,088.4$ & 3.83 \\
\hline & 1 & $192,086.8$ & 12.59 & $192,086.8$ & 5.11 \\
\hline
\end{tabular}

dynamic programming, but at considerably reduced computational effort. The second-step algorithm can provide a system operator with a fast tool that enables him to make the appropriate decisions, when called upon to adjust a schedule to accommodate for any changes in system load and/or generation.

\section{References}

Ayoub, A. K. and A. D. Patton (1971). Optimal thermal generation unit commitment. IEEE Trans., PAS-90, 1752-1756.

Baldwin, C. J., K. M. Dale and R. F. Dittrich (1959). A study of the economic shutdown of generating units in daily dispatch. AIEE Trans., PAS-78, 12721284

Fanshel, S. and E. S. Lynes (1964). Economic power generation using linear programming. IEEE Trans., PAS-83, 347-356.

Fardanesh, B. (1985). Optimal generation scheduling: a two-step approach. Doctoral dissertation, Cleveland State University, Cleveland, Ohio (to be published).

Gruhl, J., F. Schweppe and M. Ruane (1975). Unit commitment scheduling of electric power systems. System Engineering for Power: Status and Prospects, Engineering Foundation CONF750867, Henniker, New Hampshire.

Guy, J. D. (1971). Security constrained unit commitment. IEEE Trans., PAS-90, 1385-1389.

Happ, H. H. (1977). Optimal power dispatch--a comprehensive survey. IEEE Trans., 96, 841-854.

Happ, H. H., R. C. Johnson and W. J. Wright (1971). Large scale hydro-thermal unit commitment: method and results. IEEE Trans., PAS-90, 1768-1775.

IEEE Committee Report (1971). Present practices in the economic operation of power systems. Paper 71 TP 97-PWR presented at the IEEE Winter Power Meeting, New York, 31 January- 5 February.

Kennedy, T. and E. M. Mabuce (1965). Dispatch of pumped hydro storage on an interconnected hydrothermal system. IEEE Trans., PAS-84, 446-457.

Kerr, R. H., J. L. Scheidt, A. J. Fontana and J. K. Wiley (1966). Unit commitment. IEEE Trans., PAS-85, 417-421.

Lauer, G. S., D. P. Bertsekas, N. R. Sandell, Jr., and T. A. Posbergh (1982). Solution of large-scale unit commitment problems. IEEE Trans., PAS-101, 79-86.

Lowery, P. G. (1966). Generating unit commitment by dynamic programming. IEEE Trans., PAS-85, 422 -426.

Merlin, A. and P. Sandrin (1983). A new method for unit commitment at Electricité de France. IEEE Trans., PAS-102, 1218-1225.

Mukstadt, J. A. and R. C. Wilson (1968). An application of mixed-integer programming duality to scheduling thermal generating systems. IEEE Trans., PAS-87, 1968-1978.

Noakes, F. and A. Arismunder (1963). Bibliography on optimum operation of power systems: 1919-1959. AIEE Trans., PAS81, 864-871.

Pang, C. K. and H. C. Chen (1976). Optimal short term thermal unit commitment. IEEE Trans., PAS-95, 1336-1346.

Pang, C. K., G. B. Sheble and F. Albuyeh (1981). Evaluation of dynamic programming based methods and multiple area representation for thermal unit commitments. IEEE Trans., PAS-100, 1212-1218.

Rees, F. J. and R. E. Larson (1971). Computer-aided dispatching 
and operations planning for an electric utility with multiple types of generation. IEEE Trans., PAS-90, $891-899$.

Saha, T. N. and S. A. Kharparde (1978). An application of a direc method to the optimal scheduling of hydrothermal system. IEEE Trans. PAS-97, 977983
Waight, J. G., F. Albuyeh and A. Bose (1981). Sclieduling of generation and reserve margin using dynamic and lincal programming. IEEE Trans., PAS-100. 2226 2?30

Wood, W. G. (1982). Spinning reserve constrained static and dynamic economic dispatch. IEEE Trans., PAS-101. 381388 